\title{
EVOLUÇÃO GEOQUÍMICA E BALANÇO DE MASSA NA FORMAÇÃO E DEGRADAÇÃO DE PERFIS LATERÍTICOS ENCOURAÇADOS NA ÁREA DA FAZENDA PISON, VALE DO RIO TAPAJÓS, AMAZÔNIA CENTRAL
}

\author{
JOÃO HENRIQUE LARIZZATTI ${ }^{1} \&$ SONIA MARIA BARROS DE OLIVEIRA ${ }^{2}$
}

\begin{abstract}
GEOCHEMICAL EVOLUTION AND MASS BALANCE IN THE FORMATION AND DEGRADATION OF DURICRUST LATERITIC PROFILES IN THE FAZENDA PISON AREA, TAPAJÓS RIVER VALLEY, CENTRAL AMAZON In the Tapajós Province, situated in the south-central part of the Amazon craton, the landscape consists of an undulating relief which resulted from the incision of the Velhas Surface. During the Velhas geomorphological cycle (Neogene), under contrasted tropical climate, an iron duricrust lateritic mantle developed upon Proterozoic igneous rocks. Subsequent more humid climatic conditions led to the degradation of the duricrust into latosols containing dispersed nodules and pisolites. In a totally preserved profile (from 20 to $30 \mathrm{~m}$ deep), five main horizons can be distinguished, namely, from base to top: (1) a saprolitic horizon, (2) a mottled clay horizon, (3) a discontinuous ferruginous duricrust, (4) a red latosol horizon, and (5) a yellow latosol horizon. Factor analysis carried out on chemical data related to 26 samples and 24 variables reveals 3 groups of elements with distinct behavior. The first group, Si-Ca-Na-Mg-K-Mn-Ba-Cu-Zn$\mathrm{Rb}$, is characteristic of the saprolite, and represents the residual primary minerals and the manganesiferous concretions which are common at the base of the profile. The second, $\mathrm{Fe}-\mathrm{V}-\mathrm{Cr}-\mathrm{S}-\mathrm{Ga}$, corresponds to the geochemical signature of the iron duricrust, and the third, Al-Ce-La-Nb-Zr-Sr-Ti-P-Pb, is related to kaolinite, and marks either the mottled clay layer and the latosols. Mass balance has been calculated assuming the immobility of Ti. A volumetric reduction of approximately $-50 \%$ was found in the mottled clay layer and in the overlying horizons, compared to the saprolite. Besides, a strong depletion of $\mathrm{Ca}, \mathrm{Na}, \mathrm{K}$ and $\mathrm{Mg}(-80$ to $-100 \%)$, and a moderate depletion of $\mathrm{Si}(-65$ to $-80 \%)$ and $\mathrm{Al}(-45$ to $-65 \%)$ were observed along the profile. Iron is moderately enriched in the mottled clay horizon $(+50$ to $+60 \%)$, and strongly enriched in the ferricrete $(+330$ to $+700 \%)$, while in the latosols it is slightly depleted (-20 to $-38 \%)$. The absolute accumulation of iron in the ferricrete is likely due to the geochemical vertical transport of this element from the upper horizons of a previous lateritic mantle which underwent aggressive weathering. During the geochemical degradation of the ferricrete into red and yellow latosols important amounts of Fe have been leached out from the profile, and $\mathrm{Si}$ and Al have been concentrated. However, the latosols derive not only from the degradation of the ferricrete. Part of their silica content must be due to the upward transfer of material from the mottled clay horizon, by termite activity.
\end{abstract}

Keywords: ferricrete, laterization, mass balance, Tapajós valley, latosols

Resumo Na Província Tapajós, situada na porção centro-sul do craton amazônico, a paisagem é dominada por suaves colinas resultantes da incisão da superfície Velhas, de idade neógena. Durante a elaboração dessa superfície, sob clima mais seco que o atual, formou-se um manto laterítico capeado por couraça ferruginosa. Com o advento de um clima mais úmido, essa couraça entrou em desequilíbrio, transformando-se em latossolos concrecionários. No perfil intempérico completo (20 a $30 \mathrm{~m}$ de espessura) distinguemse 5 horizontes: (1) horizonte saprolítico, (2) horizonte de argila mosqueada, (3) couraça ferruginosa, (4) latossolo vermelho e (5) latossolo amarelo. Os dados químicos referentes a elementos maiores e traços dosados em amostras provenientes dos 5 horizontes da cobertura de alteração na área da Fazenda Pison foram submetidos à análise fatorial modo Q com rotação varimax (26 amostras, 24 variáveis). Os resultados permitiram identificar 3 grupos de elementos de comportamento distinto. O primeiro, compreendendo $\mathrm{Si}$, $\mathrm{Ca}, \mathrm{Na}, \mathrm{Mg}, \mathrm{K}, \mathrm{Mn}, \mathrm{Ba}, \mathrm{Cu}, \mathrm{Zn}$ e Rb, apresenta os teores mais elevados no saprólito e representa os minerais primários residuais e as concreções manganesíferas que ocorrem na base do perfil. O segundo, composto por $\mathrm{Fe}, \mathrm{V}, \mathrm{Cr}, \mathrm{S}$ e $\mathrm{Ga}$, representa a assinatura geoquímica da couraça. Finalmente, o terceiro grupo (Al, Ce, La, Nb, Zr, Sr, Ti, P e Pb) está relacionado aos horizontes mais ricos em caolinita, ou seja, o horizonte de argila mosqueada e os latossolos. O cálculo do balanço de massa isotitânio indicou mudanças volumétricas entre 50 e $60 \%$ nos horizontes sobrepostos ao saprólito. Houve forte perda de $\mathrm{Ca}, \mathrm{Na}, \mathrm{K} \mathrm{e} \mathrm{Mg}(-80$ a $-100 \%)$, e perda moderada de $\mathrm{Si}(-65 \mathrm{a}-80 \%)$ e $\mathrm{Al}(-45 \mathrm{a}-65 \%)$ ao longo do perfil. O ferro mostra ganhos absolutos moderados na argila mosqueada $(+50 \mathrm{a}+60 \%)$ e fortes na couraça $(+330 \mathrm{a}+700 \%)$; nos latossolos houve perda moderada $(-20 \mathrm{a}-38 \%)$ desse elemento. A acumulação absoluta de ferro na couraça foi provavelmente devida à migração vertical desse elemento a partir dos horizontes saprolíticos de uma cobertura laterítica pretérita. Durante a degradação da couraça para latossolos, Fe sofreu lixiviação e Si e Al concentraram-se nos latossolos. Entretanto, os latossolos não derivam apenas da degradação da couraça. Parte de seu conteúdo em sílica deve ser devida ao transporte para cima de material do horizonte de argila mosqueada pela atividade dos cupins.

Palavras-chave: couraça ferruginosa, laterização, balanço de massa, vale do rio Tapajós, latossolos

INTRODUÇÃO Nos velhos escudos da África e do Brasil, os processos de lateritização levaram ao desenvolvimento de espessos mantos intempéricos que, com freqüência, podem ser capeados por couraças ferruginosas, formadas a partir de qualquer tipo de rocha parental, e que se apresentam em grau variável desmantelamento, refletindo uma longa e complexa evolução. Com base em um grande número de detalhados estudos de caso, levados a efeito principalmente na África (Ambrosi \& Nahon

1 - LAMIN/CPRM, Avenida Pasteur, 404, Rio de Janeiro, RJ, 22290-240 Brasil, e-mail:joao@rj.cprm.gov.br

2 - Instituto de Geociências, Universidade de São Paulo, Rua do Lago, 562, Cidade Universitária, São Paulo, SP, 05508-080 Brasil, e-mail: soniaoli@usp.br 

do Rio Tapajós, Amazônia Central

1986, Nahon 1986, Boeglin \& Mazaltarim 1989, Beauvais \& Tardy 1991, Freyssinet 1991, Bilong et al. 1992, Bitom \& Volkoff 1993, Beauvais \& Colin 1993, Beauvais \& Tardy 1993, Colin et al. 1993, Beauvais \& Roquin 1996, Beauvais 1999), foi possível estabelecer que a formação das couraças ferruginosas é um fenômeno típico de regiões submetidas a clima tropical com longa estação seca e precipitação anual de 1200 a $1800 \mathrm{~mm}$. No entanto, se o clima torna-se mais úmido, as couraças entram em desequilíbrio com o meio, e sofrem degradação, o que resulta na geração de latossolos concrecionários (Nahon 1991, Tardy 1993). Assim, as couraças são valiosos indicadores paleoambientais e sua cartografia, principalmente na África, mas em menor grau também na América do Sul, Índia e Austrália, tem sido utilizada como um elemento importante na reconstituição da evolução paleoclimática desses continentes, em conseqüencia da deriva continental, ao longo dos últimos 150 milhões de anos (Tardy et al. 1991, Tardy \& Roquin 1998).

No Brasil, as formações lateríticas são mais desenvolvidas na região centro-oeste do país, sem contudo atingir a extensão e espessura que mostram na África central e ocidental (Melfi et al. 1979, Tardy et al. 1988). Na região amazônica são conhecidos perfis lateríticos portadores de couraças de natureza variada (Costa 1991). Na Amazônia ocidental, mais precisamente na região da Serra do Inajá, estado do Pará, é descrito, por exemplo, um sistema de couraças ferruginosas capeando uma superficie mais antiga, e um sistema pedológico atual a latossolos nos entalhes recentes da velha superfície (Nahon et al. 1989). No município de Belém (Horbe \& Costa 1997), e na região de Paragominas (Horbe \& Costa 1999) também são conhecidos horizontes encouraçados no seio de perfis lateríticos. Mais a oeste, no vale do rio Tapajós, escavações realizadas em muitos garimpos de ouro permitiram expor a cobertura intempérica, que se revelou formada essencialmente por latossolos que repousam diretamente sobre o saprolito. No entan- to, em alguns garimpos, foi possível observar perfis lateríticos comportando uma couraça ferruginosa, que passa vertical e lateralmente para latossolos.

Neste trabalho serão apresentados os resultados de um estudo da cobertura intempérica em um desses garimpos, utilizando a técnica do balanço de massa, com o objetivo de explicar qualitativa e quantitativamente os processos de transferência de matéria que levaram à formação e degradação da couraça ferruginosa.

ÁREA DE ESTUDO O presente estudo foi desenvolvido na área da Fazenda Pison, um dos garimpos da província aurífera do Tapajós (Santos et al. 2001), que foi prospectado pela Rio Tinto Desenvolvimentos Minerais em 1995 e que se encontra atualmente abandonado. Está situada no município de Maués, no sudeste do Estado do Amazonas (Fig. 1), à margem esquerda do rio Tapajós, a cerca de $200 \mathrm{~km}$ a sudoeste da cidade de Itaituba.

O clima da região (Am de Köppen) é quente e úmido, caracterizado por um verão moderadamente chuvoso, que se inicia em junho e termina no final de novembro, e um inverno muito chuvoso, entre dezembro e maio. A precipitação anual é próxima de 2500 $\mathrm{mm}$, a umidade relativa do ar é de cerca de $85 \%$ e a temperatura noturna/diurna oscila entre $17^{\circ} \mathrm{C} \mathrm{e} 38^{\circ} \mathrm{C}$.

Do ponto de vista geomorfológico, a região se insere na unidade morfoestrutural denominada "Planalto Rebaixado do Médio Amazonas", a qual, por sua vez, está incluída no "Domínio morfoclimático dos planaltos amazônicos rebaixados ou dissecados e das áreas colinosas revestidas por floresta densa" (Ventura et al. 1975). Esta área foi aplainada durante o Neógeno, sendo que o sistema de drenagem atual resulta do re-entalhamento iniciado no Quaternário. O pediplano neógeno corresponde à superfície de aplainamento Velhas, definida por King (1956) para o Brasil Oriental e estendida até as planícies dos rios Tocantins e Araguaia

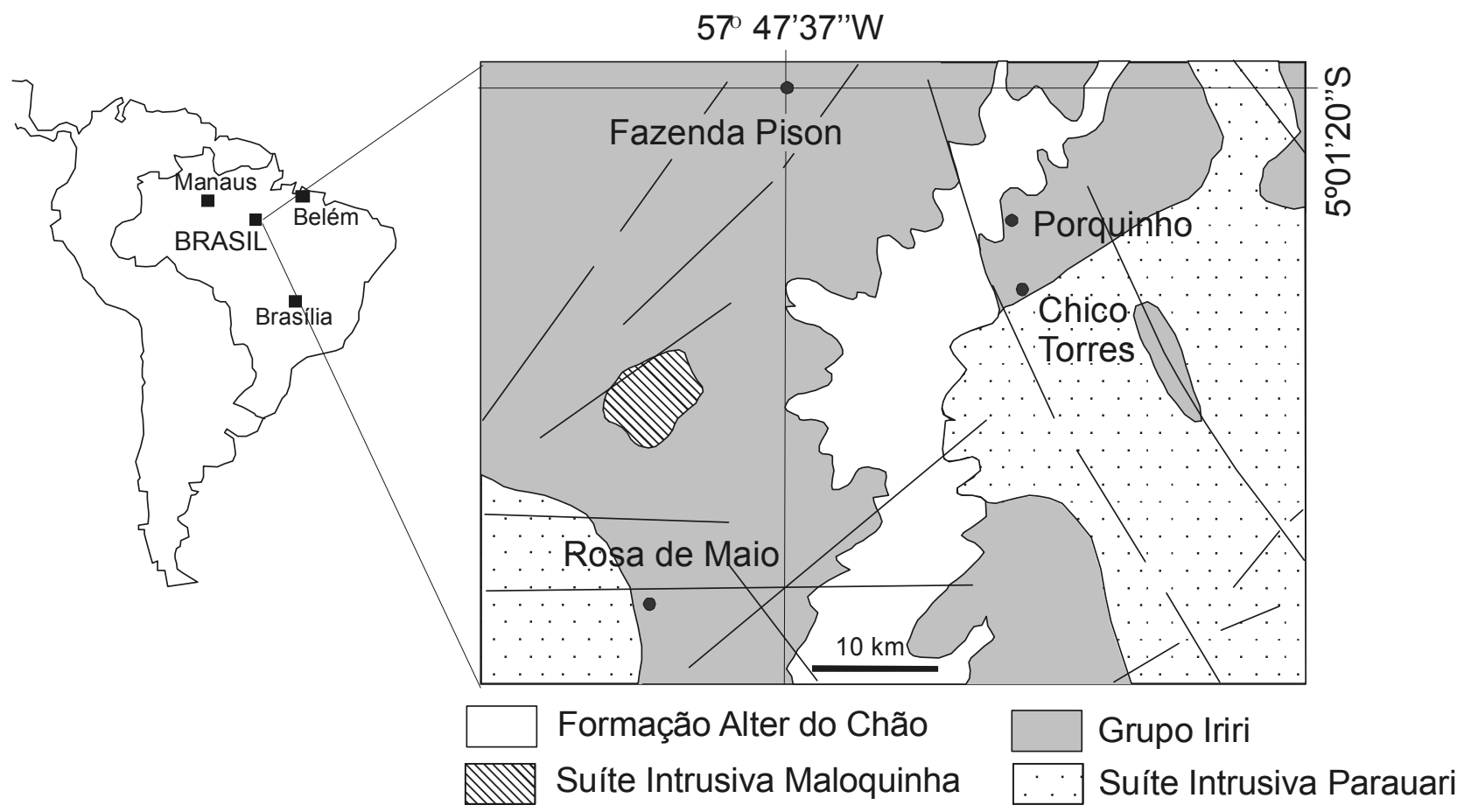

Figura 1 - Localização da área estudada e mapa geológico simplificado a partir de CPRM (1999) 
por Braun (1971). Sua origem estaria relacionada ao soerguimento do continente, com conseqüente retomada da erosão no final do Terciário.

Geologicamente, a região do Tapajós está contida na porção sul do Craton Amazônico e constitui um dos quatro domínios pertencentes ao cinturão orogênico paleoproterozóico conhecido como Tapajós-Parima. As principais unidades litoestratigráficas presentes no domínio Tapajós são granitóides cálcio-alcalinos e, subordinadamente, seqüências metassedimentares. No citado cinturão, e especialmente no domínio Tapajós, são conhecidos numerosos depósitos e ocorrências auríferas (Santos et al. 2001).

$\mathrm{Na}$ área da Fazenda Pison, o relevo é suavemente ondulado, e consiste em morrotes meia-laranja de encostas suaves, cobertos por floresta tropical úmida. As altitudes situam-se entre $140 \mathrm{~m}$ nos vales, e $200 \mathrm{~m}$ nos topos. O padrão de drenagem é dendrítico e o principal curso d'água é o Igarapé Nambezinho. Afloram rochas vulcânicas ácidas do Grupo Iriri e rochas intrusivas graníticas da Suíte Intrusiva Maloquinha (Figura 1), todas pertencentes ao Supergrupo Uatumã (CPRM 1999). As rochas do Grupo Iriri e da Suíte Intrusiva Maloquinha são cortadas por veios de quartzo auríferos, objetos de garimpagem.

PERFIL DE ALTERAÇÃo As excavações executadas para a extração do ouro expuseram o perfil de alteração intempérica nos topos, meia-encostas e base das colinas, permitindo conhecer não só sua estruturação vertical, como também lateral (Fig. 2). A rocha fresca não aflora, sendo conhecida apenas através de furos de sondagem. Segundo relatório interno da empresa que realizou a pesquisa mineral, trata-se de um granófíro fanerítico muito fino da Suíte Intrusiva Maloquinha, intensamente afetado por alteração hidrotermal de natureza potássica, e cortado por veios de quartzo de espessura milimétrica a centimétrica arranjados em estrutura stockwork. Os principais minerais presentes na rocha são quartzo, feldspato alcalino e biotita (RTDM 1995).

O perfil de alteração completo (Fig. 3) compreende, da base para o topo, os seguintes horizontes: saprólito (espessura maior que $10 \mathrm{~m})$, argila mosqueada $(0-2 \mathrm{~m}$ de espessura), couraça ferruginosa ( 0 - $1 \mathrm{~m}$ de espessura), latossolo vermelho ( 0 - $7 \mathrm{~m}$ de espessura) e latossolo amarelo ( 1 - $4 \mathrm{~m}$ de espessura).

O saprólito é um material coeso, vermelho claro e, de modo

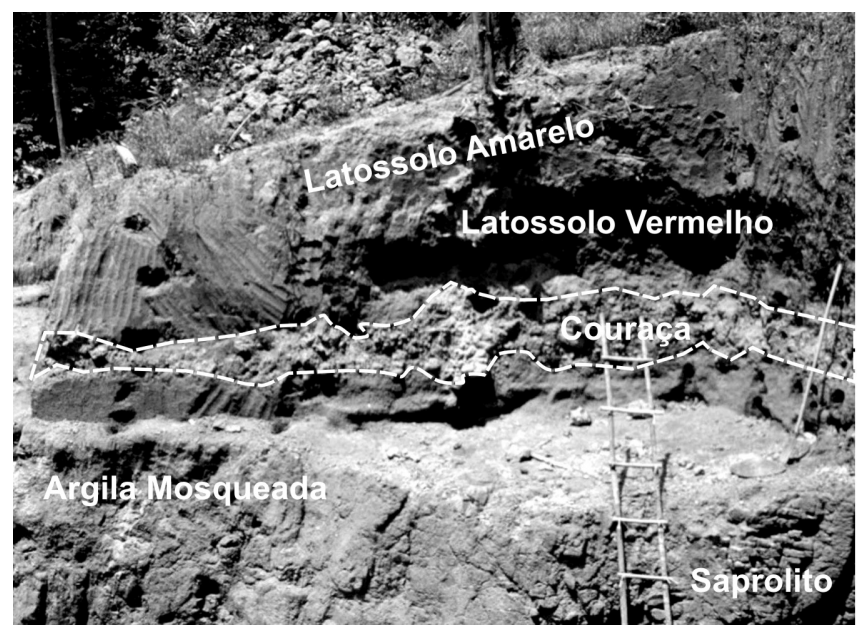

Figura 2 - Perfil laterítico da Fazenda Pison. geral, apresenta a estrutura original da rocha bem preservada, o que é sublinhado pela conservação da posição original dos veios de quartzo. Apenas na sua porção superior, na passagem para a argila mosqueada, registram-se indícios de obliteração da estrutura original e o material torna-se menos coeso, podendo ser quebrado facilmente com a mão.

O horizonte de argila mosqueada divide-se em duas porções bastante distintas. Na sua base é caracterizado por uma estrutura em blocos, e consiste em fragmentos vermelhos claros centimétricos a decimétricos do granófiro intemperizado envolvidos em uma matriz vermelha escura, argilosa, rica em óxi-hidróxidos de Fe. No contato com a matriz, os fragmentos de granófiro estão manchados por óxi-hidróxidos de $\mathrm{Fe}$, que preenchem fraturas e se concentram na periferia dos grãos e nos espaços intergranulares. Em direção ao topo não se torna mais possível identificar os restos do granófiro intemperizado. O material torna-se mais homogêneo, e é composto de uma matriz de cor amarela avermelhada com manchas milimétricas a centimétricas mais escuras e avermelhadas, indicando maior concentração do ferro. A abundância das manchas em relação ao fundo matricial claro e a coesão do material componente das manchas aumentam em direção ao topo, numa passagem gradual para a couraça.

A couraça é material litificado, exibe estrutura nodular, e compõe-se de nódulos centimétricos vermelhos escuros muito endu-

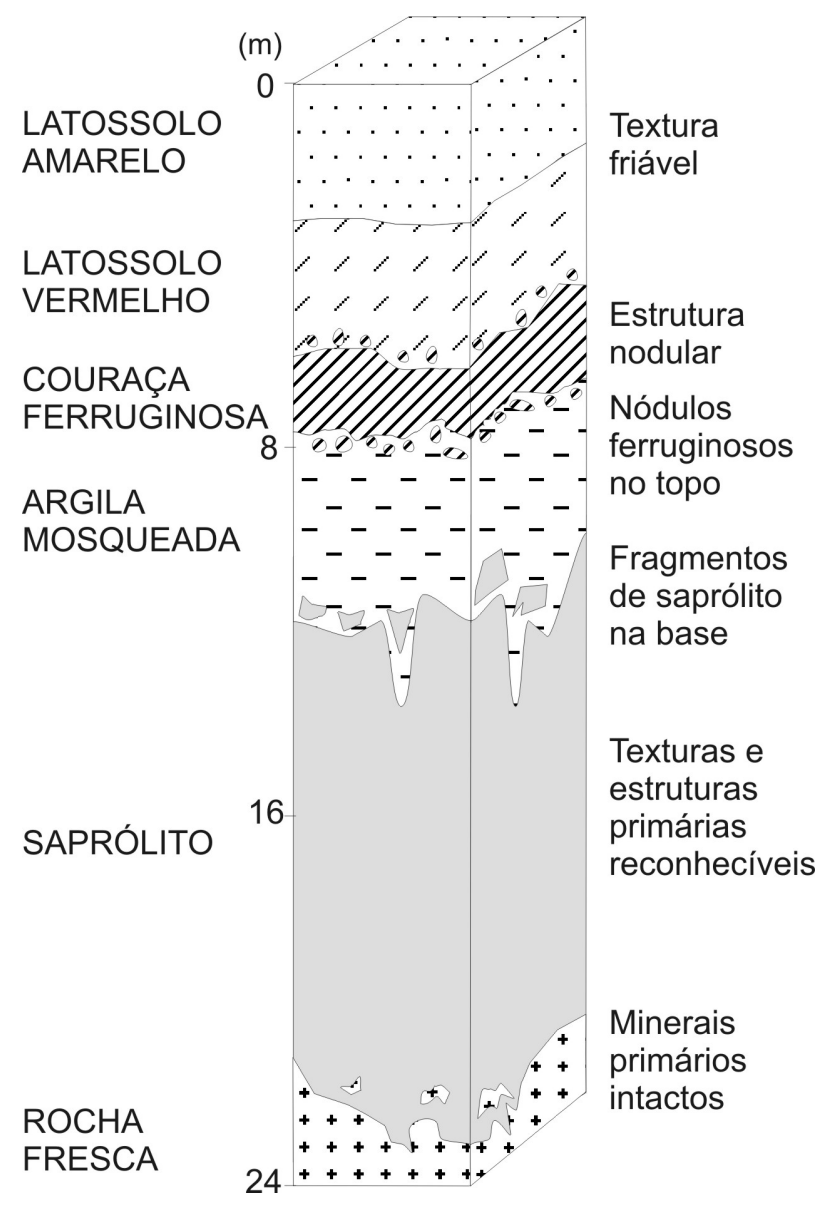

Figura 3 - Perfil laterítico sintético com breve descrição dos horizontes. 
recidos imersos em uma matriz vermelha amarelada. Em direção ao topo e lateralmente, passa a produtos nodulares e pisolíticos. A transição para o horizonte superior dá-se em poucos centímetros. A quantidade de nódulos e pisólitos vai diminuindo em favor de uma matriz areno-argilosa que se torna mais abundante em direção ao latossolo vermelho.

Este é um solo friável, de cor marrom avermelhada, consistindo de matriz argilosa que contém nódulos e pisólitos ferruginosos, mais abundantes na base do horizonte. Ocorrem também grãos de quartzo e fragmentos de vênulas de quartzo imersos na matriz. Em direção ao topo, o latossolo vermelho gradualmente passa para um latossolo amarelo, friável, cuja matriz argilosa contém poucos nódulos e pisólitos ferruginosos, bem como fragmentos de veios de quartzo. Esses elementos mais grossos diminuem em quantidade em direção ao topo do horizonte. Este está sempre coberto por uma camada de matéria orgânica (folhas, galhos, etc.), cuja espessura varia de poucos centímetros nos topos dos morros, até meio metro nas baixadas.

Os horizontes de argila mosqueada e de couraça não são contínuos. Ocorrem mais bem desenvolvidos em meia encosta, adelgaçando-se lateralmente para dar lugar a um latossolo concrecionário que repousa diretamente sobre o saprólito. $\mathrm{O}$ latossolo vermelho apresenta espessura maior nas zonas topograficamente mais elevadas e diminui em direção à base das colinas, desaparecendo nas proximidades das drenagens. $\mathrm{O}$ latossolo amarelo recobre o latossolo vermelho ou o saprólito nos locais onde o latossolo vermelho está ausente; é o material de mais ampla distribuição na área na Fazenda Pison, sendo praticamente contínuo em toda a região. Sua continuidade é apenas interrompida pelas drenagens, onde é recoberto por aluviões recentes. A espessura do latossolo amarelo é maior nos altos topográficos, de até $4 \mathrm{~m}$, e se adelgaça nas encostas das colinas (até $1 \mathrm{~m}$ ), e tornase de novo um pouco maior nas áreas baixas (até $2 \mathrm{~m}$ ).

\section{AMOSTRAGEM, TÉCNICAS ANALÍTICAS E TRATAMEN-} TO DE DADOS O regolito foi amostrado na parte central de uma trincheira vertical de aproximadamente $15 \mathrm{~m}$ de profundidade, onde a couraça ferruginosa apresenta seu desenvolvimento máximo (Fig. 4). Foram coletadas amostras de 3 perfis verticais (perfis 14, 15 e 18), espaçados entre si de um a três metros, resultando num total de 6 amostras de latossolo amarelo (LA), 6 de latossolo vermelho (LV), 6 de couraça (C), 5 de argila mosqueada (AM) e 3

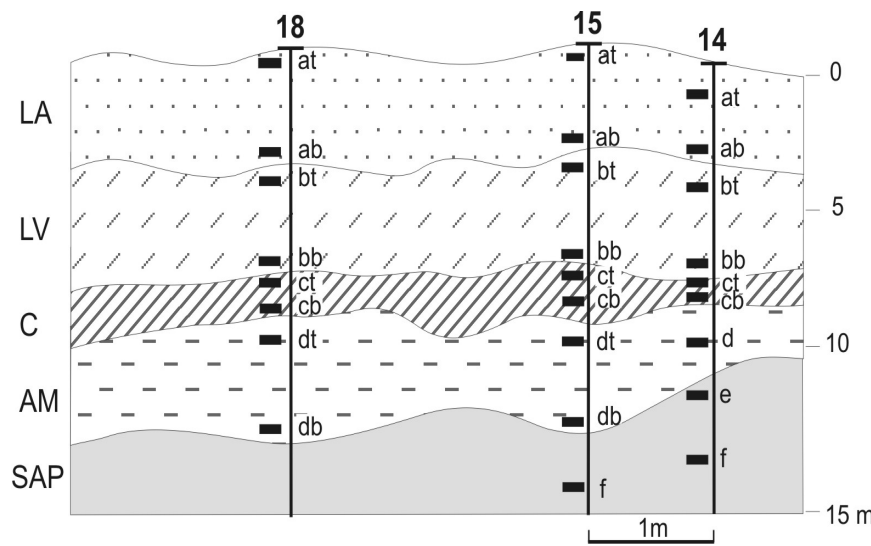

Figura 4 - Localização das amostras coletadas no perfis laterítico ( $S A P=$ saprólito, $A M=$ argila mosqueada, $C=$ couraça, $L A=$ latossolo amarelo, $L V=$ latossolo vermelho) de saprólito, sendo duas delas de saprólito pouco evoluído (SAP1) e a outra de saprólito bem mais evoluído (SAP2). Sempre que possível, foram amostrados o topo e a base de cada horizonte.

Todas as amostras indeformadas foram impregnadas com resina epóxi e lâminas delgadas foram confeccionadas. Alguns fragmentos de amostras indeformadas foram parafinados para determinação da densidade aparente. Referente aos latossolos, foram coletadas amostras indeformadas de volume bem definido para a determinação deste mesmo parâmetro. $\mathrm{O}$ restante das amostras (cerca de $2 \mathrm{~kg}$ de cada) foi britado, se necessário, quarteado e moído a $<80$ mesh. Essas amostras foram submetidas a análise mineralógica por difração de raios-X e a análise química para elementos maiores e traços por fluorescência de raios-X. Os limites de detecção dos elementos maiores foram de $0,01 \% \mathrm{e}$, para os traços, os seguintes: Ba-20ppm, Ce-15ppm, Cr-10ppm, Cu-10ppm, Ga-3ppm, La-10ppm, Nb-4ppm, Pb-5ppm, Rb-5ppm, S-10ppm, Sr5ppm, V-5ppm, Y-5ppm, Zn-5ppm.

A quantificação das transferências de massa durante o intemperismo foi obtida pelo calculado do balanço de massa, de acordo com os princípios estabelecidos por Brimhall \& Dietrich (1987) e Brimhall et al. (1991). Segundo esses autores, a mudança de volume em um determinado horizonte w é expressa por:

$$
\varepsilon_{i, w}=\left(\left(\delta_{p} C_{i, p}\right) /\left(\delta_{w} C_{i, w}\right)\right)-1
$$

onde i é o elemento considerado imóvel durante o intemperismo, $\delta_{\mathrm{p}}$ é a densidade aparente (bulk density) do material parental, $\delta_{w}$ é a densidade aparente do material do horizonte $\mathrm{w}, \mathrm{C}_{\mathrm{i}, \mathrm{p}}$ é a concentração do elemento imóvel usado como referência no material parental e $\mathrm{C}_{\mathrm{i}, \mathrm{w}}$ é a concentração do elemento imóvel usado como referência no horizonte $\mathrm{w}$. Se $\varepsilon=0$, a alteração é isovolumétrica. Valores de e negativos significam que houve acomodação (colapso) do material alterado, enquanto valores de e positivos indicam dilatação.

Os ganhos (valores positivos) ou perdas (valores negativos) de determinada quantidade um elemento j em relação ao seu conteúdo no material parental se expressa pela função de transporte de massa $\tau$ :

$$
\tau=\left(\left(\delta_{w} C_{j, w} / \delta_{p} C_{j, p}\right)\left(\varepsilon_{i, w}+1\right)\right)-1
$$

\section{CARACTERIZAČ̃̃ MINERALÓGICA E PETROGRÁFICA} DOS MATERIAIS DO PERFIL Saprólito No saprólito, o quartzo é o mineral mais abundante, seguido pela mica e a caolinita. Como minerais acessórios, foram identificados pseudomorfos de hematita segundo magnetita, zircão, rutilo, anatásio, pirita e goethita. Principalmente na base do horizonte, observam-se esparsas e milimétricas concreções negras formadas por óxidos de manganês. Os feldspatos da rocha estão totalmente alterados e, no saprólito mais alterado, observa-se modificação das propriedades ópticas das micas, como mudanças no relevo (que se torna mais baixo) e no pleocroísmo (cores de interfeência vivas são substituídas por tonalidades mais acinzentadas), indicando transição pseudomórfica também para caolinita. A principal diferença entre o saprólito menos evoluído e o mais evoluído é o maior grau de alteração das micas, já que em ambos não existem mais traços de feldspato e os grãos de quartzo permanecem inalterados em suas posições originais.

Argila mosqueada Na sua base, este horizonte é bastante poroso e consiste em matriz argilo-ferruginosa que engloba alterorelictos do granófiro. Apresenta significativa diminuição no 
conteúdo de mica e um aumento do conteúdo de caolinita em relação ao saprólito. Observações feitas ao microscópio óptico e eletrônico mostram que os óxi-hidróxidos de ferro começam a preencher as descontinuidades presentes na rocha (espaços intergranulares e espaços interlamelares nas micas), o que contribui à destruição da textura primária, e ao isolamento dos grãos de quartzo, que acabam envolvidos em uma matriz caolinítica rica em Fe e muito porosa. A textura primária desaparece com o aumento da quantidade da matriz caolinítica e o isolamento dos grãos de quartzo e de algumas palhetas de mica. Por sua vez, os cristais de caolinita não apresentam orientação perceptível.

O topo do horizonte é mais compacto que sua parte inferior. Compõe-se de uma matriz argilo-ferruginosa com finos grãos de quartzo que apresentam discretos sinais de corrosão. Nela quase não há mais mica, que está praticamente toda alterada em caolinita. Por outro lado, os oxi-hidróxidos de ferro (dominantemente goethita) são mais abundantes, concentrando-se em domínios de cor marrom avermelhada, de bordas difusas, distribuídos irregularmente na matriz. Estes domínios correspondem às manchas avermelhadas descritas em afloramento, e tornam-se cada vez maiores, mais abundantes e mais compactos em direção ao topo do horizonte.

Como minerais acessórios foram identificados na base do horizonte de argila mosqueada zircão, pseudomorfos de hematita segundo magnetita, rutilo, anatásio e raros grãos de pirita encapsulados no quartzo. No topo do horizonte, estão presentes os mesmos minerais, exceto a pirita.

Couraça Na couraça dominam os óxi-hidróxidos de ferro, seguidos pela caolinita e o quartzo em proporções significativamente inferiores àquelas observadas no horizonte de argila mosqueada; a mica está praticamente ausente. Os minerais acessórios são zircão, pseudomorfos de hematita a partir de magnetita, rutilo e anatásio.

A couraça apresenta estrutura nodular. Os nódulos são de composição dominantemente hematítica e estão imersos em uma matriz areno-argilosa ferruginosa endurecida, bastante porosa, e composta por caolinita, goethita e grãos de quartzo bastante corroídos. Os poros aparecem freqüentemente como moldes negativos de grãos de quartzo e, em alguns casos, restos de grãos de quartzo ocupam parcialmente os poros, indicando que há expressiva dissolução desse mineral. Na parte interior dos nódulos observam-se indícios da textura da rocha (litorelictos) ou de materiais mais evoluídos do saprólito ou da argila mosqueada (pedorelictos).

Em direção ao topo do horizonte inicia-se a degradação da couraça, causada pela desferrificação da matriz, o que a torna friável e leva uma progressiva individualização dos nódulos. Estes adquirem córtex amarelado, geralmente bandado, composto por goethita aluminosa.

Latossolo vermelho O latossolo vermelho possui matriz argilosa porosa e avermelhada, composta de caolinita, hematita, goethita e grãos de quartzo, onde estão dispersos nódulos inteiros ou fragmentados, pedo ou litoreliquiares, com ou sem córtex, e fragmentos de quartzo proveniente de veios.

Este horizonte apresenta um aumento substancial do conteúdo de caolinita e quartzo em relação ao horizonte subjacente e complementarmente uma diminuição do conteúdo de oxi-hidróxidos de ferro. A presença de hematita confere a cor vermelha ao latossolo. Os minerais acessórios são zircão, pseudomorfos de hematita segundo magnetita e rutilo.

Tabela 1 - Composição química de amostras dos horizontes do perfil laterítico (óxidos em \%, elementos traço em ppm)

\begin{tabular}{|c|c|c|c|c|c|c|c|c|c|c|c|c|c|c|c|c|c|c|c|c|c|c|c|c|}
\hline LA & $\mathrm{SiO}_{2}$ & $\mathrm{Al}_{2} \mathrm{O}_{3}$ & $\mathrm{Fe}_{2} \mathrm{O}_{3}$ & $\mathrm{MnO}$ & $\mathrm{MgO}$ & $\mathrm{Na}_{2} \mathrm{O}$ & $\mathrm{CaO}$ & $\mathrm{K}_{2} \mathrm{O}$ & $\mathrm{TiO}_{2}$ & $\mathrm{P}_{2} \mathrm{O}_{5}$ & $\mathrm{Ba}$ & $\mathrm{Ce}$ & $\mathrm{Cr}$ & $\mathrm{Cu}$ & $\mathrm{Ga}$ & $\mathrm{La}$ & $\mathrm{Nb}$ & $\mathrm{Pb}$ & $\mathrm{Rb}$ & $\mathrm{S}$ & $\mathrm{Sr}$ & V & $\mathrm{Y}$ & $\mathrm{Zn}$ \\
\hline$a b-14$ & 65,2 & 18,8 & 6,1 & 0,02 & 0,06 & 0,00 & 0,01 & 0,12 & 0,96 & 0,06 & 104 & 97 & 51 & 12 & 23 & 51 & 10 & 43 & 4 & 230 & 43 & 92 & 28 & 19 \\
\hline at-14 & 64,3 & 19,3 & 6,3 & 0,02 & 0,05 & 0,01 & 0,01 & 0,12 & 0,99 & 0,06 & 134 & 104 & 49 & 13 & 25 & 53 & 8 & 45 & 5 & 220 & 47 & 86 & 24 & 18 \\
\hline$a b-15$ & 64,0 & 19,4 & 6,3 & 0,02 & 0,05 & 0,00 & 0,01 & 0,10 & 1,00 & 0,06 & 117 & 100 & 49 & 13 & 25 & 50 & 13 & 49 & 4 & 220 & 47 & 91 & 25 & 18 \\
\hline at-15 & 64,6 & 18,6 & 6,2 & 0,02 & 0,06 & 0,00 & 0,01 & 0,08 & 1,00 & 0,06 & 106 & 94 & 45 & 10 & 25 & 47 & 13 & 43 & 2 & 310 & 44 & 86 & 25 & 17 \\
\hline ab-18 & 64,2 & 19,5 & 6,3 & 0,02 & 0,07 & 0,02 & 0,01 & 0,12 & 0,96 & 0,06 & 124 & 88 & 48 & 15 & 25 & 49 & 9 & 42 & 8 & 220 & 45 & 77 & 26 & 20 \\
\hline $\begin{array}{r}\text { at-18 } \\
\text { LV }\end{array}$ & 63,6 & 19,4 & 6,4 & 0,02 & 0,06 & 0,00 & 0,01 & 0,07 & 0,99 & 0,06 & 122 & 81 & 49 & 17 & 26 & 53 & 11 & 41 & 2 & 220 & 45 & 81 & 25 & 19 \\
\hline bb-14 & 64,0 & 19,7 & 6,5 & 0,02 & 0,06 & 0,02 & 0,01 & 0,23 & 0,95 & 0,06 & 128 & 105 & 48 & 21 & 26 & 55 & 13 & 44 & 12 & 190 & 43 & 89 & 27 & 18 \\
\hline bt-14 & 62,1 & 20,5 & 6,7 & 0,02 & 0,08 & 0,00 & 0,01 & 0,21 & 1,01 & 0,06 & 129 & 102 & 48 & 24 & 28 & 52 & 14 & 45 & 13 & 220 & 48 & 88 & 28 & 21 \\
\hline bb-15 & 62,1 & 19,6 & 7,9 & 0,02 & 0,07 & 0,01 & 0,01 & 0,29 & 0,90 & 0,06 & 132 & 111 & 72 & 20 & 28 & 54 & 13 & 52 & 19 & 160 & 42 & 111 & 29 & 20 \\
\hline bt- 15 & 63,7 & 19,8 & 6,4 & 0,02 & 0,07 & 0,00 & 0,01 & 0,20 & 0,96 & 0,06 & 128 & 117 & 48 & 16 & 26 & 54 & 12 & 42 & 12 & 190 & 46 & 80 & 30 & 18 \\
\hline bb-18 & 62,1 & 20,6 & 6,9 & 0,02 & 0,06 & 0,00 & 0,01 & 0,24 & 0,94 & 0,06 & 129 & 116 & 53 & 23 & 28 & 54 & 14 & 44 & 15 & 170 & 50 & 82 & 31 & 25 \\
\hline $\begin{array}{c}\text { bt- } 18 \\
\text { C }\end{array}$ & 62,7 & 20,3 & 6,6 & 0,02 & 0,07 & 0,00 & 0,01 & 0,16 & 0,97 & 0,06 & 112 & 101 & 46 & 18 & 28 & 53 & 11 & 47 & 12 & 210 & 45 & 84 & 29 & 21 \\
\hline cb-14 & 17,6 & 11,4 & 58,4 & 0,01 & 0,03 & 0,01 & 0,01 & 0,06 & 0,61 & 0,04 & 12 & 38 & 269 & 19 & 34 & 7 & 1 & 46 & 3 & 410 & 15 & 1268 & 12 & 13 \\
\hline ct-14 & 34,5 & 15,5 & 38,6 & 0,01 & 0,03 & 0,00 & 0,00 & 0,10 & 0,79 & 0,05 & 57 & 62 & 326 & 23 & 37 & 15 & 10 & 42 & 5 & 330 & 25 & 988 & 18 & 14 \\
\hline cb-15 & 32,0 & 13,3 & 43,6 & 0,02 & 0,05 & 0,00 & 0,00 & 0,13 & 0,76 & 0,05 & 85 & 83 & 311 & 20 & 38 & 27 & 3 & 45 & 11 & 350 & 27 & 1661 & 18 & 16 \\
\hline ct-15 & 42,4 & 17,1 & 29,1 & 0,02 & 0,05 & 0,00 & 0,01 & 0,12 & 0,82 & 0,05 & 105 & 64 & 338 & 17 & 35 & 35 & 5 & 57 & 7 & 270 & 33 & 990 & 20 & 9 \\
\hline cb-18 & 44,8 & 10,7 & 34,8 & 0,01 & 0,05 & 0,00 & 0,01 & 0,07 & 0,50 & 0,04 & 45 & 56 & 109 & 14 & 19 & 23 & 4 & 46 & 3 & 300 & 19 & 290 & 11 & 9 \\
\hline $\begin{array}{r}\text { ct-18 } \\
\text { AM }\end{array}$ & 42,7 & 17,2 & 28,9 & 0,02 & 0,04 & 0,01 & 0,01 & 0,08 & 0,82 & 0,05 & 96 & 72 & 321 & 13 & 33 & 40 & 10 & 52 & 1 & 310 & 33 & 618 & 24 & 13 \\
\hline $\mathrm{d}-14$ & 57,1 & 18,9 & 14,0 & 0,03 & 0,08 & 0,01 & 0,01 & 0,35 & 1,01 & 0,07 & 142 & 109 & 154 & 19 & 26 & 52 & 14 & 54 & 21 & 180 & 49 & 201 & 29 & 15 \\
\hline $\mathrm{db}-15$ & 61,6 & 17,0 & 12,5 & 0,02 & 0,08 & 0,01 & 0,01 & 0,38 & 0,85 & 0,06 & 143 & 106 & 144 & 18 & 26 & 44 & 6 & 53 & 25 & 150 & 38 & 146 & 27 & 19 \\
\hline dt- 15 & 56,7 & 19,5 & 14,1 & 0,03 & 0,09 & 0,01 & 0,01 & 0,33 & 0,98 & 0,07 & 177 & 112 & 133 & 24 & 26 & 55 & 13 & 54 & 23 & 210 & 50 & 177 & 25 & 17 \\
\hline db-18 & 55,1 & 19,2 & 15,5 & 0,03 & 0,07 & 0,01 & 0,01 & 0,23 & 1,00 & 0,07 & 139 & 111 & 160 & 22 & 28 & 57 & 11 & 57 & 12 & 180 & 47 & 186 & 24 & 19 \\
\hline $\begin{array}{r}\text { dt-18 } \\
\text { SAP }\end{array}$ & 61,0 & 19,2 & 9,9 & 0,02 & 0,07 & 0,01 & 0,01 & 0,21 & 0,97 & 0,06 & 150 & 108 & 106 & 20 & 28 & 55 & 14 & 48 & 11 & 190 & 49 & 135 & 26 & 15 \\
\hline $\mathrm{e}-14$ & 76,9 & 11,5 & 5,3 & 0,02 & 0,14 & 0,02 & 0,02 & 1,77 & 0,38 & 0,03 & 219 & 73 & 26 & 31 & 20 & 29 & 5 & 27 & 113 & 120 & 24 & 56 & 28 & 14 \\
\hline$f-14$ & 72,2 & 15,9 & 3,8 & 0,05 & 0,26 & 0,04 & 0,02 & 2,65 & 0,38 & 0,02 & 261 & 58 & 63 & 43 & 24 & 48 & 8 & 30 & 218 & 90 & 10 & 43 & 35 & 50 \\
\hline$f-15$ & 71,7 & 15,9 & 3,8 & 0,05 & 0,25 & 0,04 & 0,04 & 2,67 & 0,38 & 0,02 & 262 & 62 & 62 & 39 & 24 & 40 & 11 & 23 & 220 & 80 & 9 & 44 & 38 & 51 \\
\hline
\end{tabular}


Latossolo amarelo O latossolo amarelo é semelhante ao latossolo vermelho em textura e composição, com a diferença que neste predomina a goethita sobre a hematita. A matriz é porosa e formada por caolinita, goethita e diminutos grãos de quartzo. Ela sustenta fragmentos de quartzo e nódulos ferruginosos em menor quantidade que no latossolo vermelho. Os minerais acessórios são os mesmos que os encontrados no horizonte subjacente.

GEOQUÍMICA A Tabela 1 mostra a composição química de amostras provenientes de cada horizonte do perfil de alteração. No saprólito, a composição química é relativamente próxima da de uma rocha granítica, refletindo o grau de alteração ainda moderado desse material. A porcentagem de $\mathrm{K}_{2} \mathrm{O}$ é elevada, pois as micas se encontram pouco intemperizadas. No entanto, os teores de $\mathrm{Na}_{2} \mathrm{O}$ e $\mathrm{CaO}$ já são muito baixos, em decorrência do avançado estado de alteração dos feldspatos para caolinita.

No horizonte de argila mosqueada, tem início realmente a concentração do ferro, cujo teor atinge valores geralmente superiores a $10 \%$ de $\mathrm{Fe}_{2} \mathrm{O}_{3}$, bem acima dos 3 a 5\% encontrados no saprólito. $\mathrm{Na}$ argila mosqueada, o teor de $\mathrm{K}_{2} \mathrm{O}$ é bastante baixo, o que leva a um predomínio de $\mathrm{SiO}_{2}, \mathrm{Al}_{2} \mathrm{O}_{3}$ e $\mathrm{Fe}_{2} \mathrm{O}_{3}$, típico de produtos lateríticos, e que vai prevalecendo nos horizontes superiores do perfil. A couraça é o horizonte onde os teores de ferro atingem os valores mais elevados, principalmente na base, onde chegam a mais de $58 \% \mathrm{Fe}_{2} \mathrm{O}_{3}$. Em compensação, os teores de $\mathrm{SiO}_{2}$ e $\mathrm{Al}_{2} \mathrm{O}_{3}$ diminuem. Finalmente, nos latossolos, os teores de $\mathrm{Fe}_{2} \mathrm{O}_{3}$ caem a valores entre 6 e $7 \%$ e as concentrações de $\mathrm{Al}_{2} \mathrm{O}_{3}$ e $\mathrm{SiO}_{2}$ aumentam até valores de 20 e $60 \%$, respectivamente. De modo geral, não há diferença significativa na composição química entre os dois latossolos. Apenas pode-se notar um ligeiro empobrecimento em Fe no latossolo amarelo em comparação como o latossolo vermelho.
A Tabela 2 contém os valores médios e os desvios-padrões respectivos para os teores dos elementos maiores e traço em cada horizonte. A partir desses dados e da identificação das principais fases presentes por difração de raios X, foi calculada uma composição mineralógica normativa média (Nyobe 1991), mostrada na Tabela 3.

Com a finalidade de definir as relações entre os elementos analisados, foi efetuada uma análise fatorial modo Q para o conjunto de 26 amostras analisadas para 24 elementos utilizando o software STATISTICA. Foram selecionados 2 fatores e efetuada a rotação varimax. Os loadings para cada variável em cada fator e os scores de cada fator para cada amostra estão na Tabela 4, assim como as comunalidades para cada variável no modelo de 2 fatores. A figura 5 mostra a projeção dos loadings no diagrama F1 versus $\mathrm{F} 2$.

Os resultados mostram que o uso do modelo de 2 fatores, que dá conta de $81 \%$ da variança total, foi adequado para a caracterização dos dados. O primeiro fator, F1, é responsável por $45 \%$ da variança total e $\mathrm{F} 2$ por $36 \%$. Os valores das comunalidades, os quais são, em sua maior parte, próximos de 1, indicam que o com-

Tabela 3 - Composição mineralógica normativa média dos horizontes do perfil laterítico (\% em peso).

\begin{tabular}{cccccc}
\hline & Qz & H + G & Mica & Caol. & Qz/Caol. \\
\hline LA & 43 & 7 & 1 & 49 & 0,88 \\
LV & 39 & 7 & 1 & 51 & 0,76 \\
C & 24 & 42 & 1 & 33 & 0,72 \\
AM & 38 & 14 & 3 & 45 & 0,84 \\
SAP2 & 53 & 6 & 18 & 23 & 2,30 \\
SAP1 & 47 & 4 & 27 & 22 & 2,13 \\
\hline
\end{tabular}

Tabela 2 - Composição química média da cobertura laterítica. Óxidos em \%. Elementos traço em ppm.

\begin{tabular}{|c|c|c|c|c|c|c|c|c|c|c|c|}
\hline & $\begin{array}{c}\text { LA } \\
(6) \\
\text { media }\end{array}$ & Desvio $\mathrm{p}$ & LV (6) & Desvio $\mathrm{p}$ & $C(6)$ & Desvio $\mathrm{p}$ & $\mathrm{AM}(5)$ & Desvio $\mathrm{p}$ & SAP2 (1) & SAP1 (2) & Desvio $\mathrm{p}$ \\
\hline $\mathrm{SiO}_{2}$ & 64,32 & 0,55 & 62,78 & 0,87 & 35,65 & 10,17 & 58,29 & 2,86 & 76,86 & 71,95 & 0,39 \\
\hline $\mathrm{Al}_{2} \mathrm{O}_{3}$ & 19,17 & 0,36 & 20,10 & 0,45 & 14,21 & 2,84 & 18,77 & 1,04 & 11,54 & 15,89 & 0,05 \\
\hline $\mathrm{Fe}_{2} \mathrm{O}_{3}$ & 6,27 & 0,11 & 6,82 & 0,55 & 38,90 & 11,11 & 13,19 & 2,15 & 5,25 & 3,84 & 0,01 \\
\hline $\mathrm{MnO}$ & 0,02 & 0,00 & 0,02 & 0,00 & 0,01 & 0,00 & 0,03 & 0,00 & 0,02 & 0,05 & 0,00 \\
\hline $\mathrm{MgO}$ & 0,06 & 0,01 & 0,07 & 0,01 & 0,04 & 0,01 & 0,08 & 0,01 & 0,14 & 0,26 & 0,01 \\
\hline $\mathrm{CaO}$ & 0,01 & 0,00 & 0,01 & 0,00 & 0,00 & 0,01 & 0,01 & 0,00 & 0,02 & 0,02 & 0,00 \\
\hline $\mathrm{Na}_{2} \mathrm{O}$ & 0,00 & 0,01 & 0,00 & 0,01 & 0,00 & 0,01 & 0,01 & 0,00 & 0,02 & 0,04 & 0,00 \\
\hline $\mathrm{K}_{2} \mathrm{O}$ & 0,10 & 0,02 & 0,22 & 0,04 & 0,09 & 0,03 & 0,30 & 0,08 & 1,77 & 2,66 & 0,01 \\
\hline $\mathrm{TiO}_{2}$ & 0,98 & 0,02 & 0,96 & 0,03 & 0,72 & 0,13 & 0,96 & 0,07 & 0,38 & 0,38 & 0,00 \\
\hline $\mathrm{P}_{2} \mathrm{O}_{5}$ & 0,06 & 0,00 & 0,06 & 0,00 & 0,05 & 0,01 & 0,06 & 0,00 & 0,03 & 0,02 & 0,00 \\
\hline $\mathrm{Ba}$ & 118 & 11 & 126 & 7 & 67 & 35 & 150 & 16 & 219 & 262 & 1 \\
\hline $\mathrm{Ce}$ & 94 & 8 & 109 & 7 & 63 & 15 & 109 & 2 & 73 & 60 & 3 \\
\hline $\mathrm{Cr}$ & 49 & 2 & 53 & 10 & 279 & 87 & 139 & 21 & 26 & 63 & 1 \\
\hline $\mathrm{Cu}$ & 13 & 2 & 20 & 3 & 18 & 4 & 21 & 2 & 31 & 41 & 3 \\
\hline $\mathrm{Ga}$ & 25 & 1 & 27 & 1 & 33 & 7 & 27 & 1 & 20 & 24 & 0 \\
\hline $\mathrm{La}$ & 51 & 2 & 54 & 1 & 22 & 17 & 53 & 5 & 29 & 44 & 6 \\
\hline $\mathrm{Nb}$ & 11 & 2 & 13 & 1 & 6 & 4 & 12 & 3 & 5 & 10 & 2 \\
\hline $\mathrm{Pb}$ & 44 & 3 & 46 & 4 & 48 & 5 & 53 & 3 & 27 & 27 & 5 \\
\hline $\mathrm{Rb}$ & 4 & 2 & 14 & 3 & 5 & 4 & 18 & 6 & 113 & 219 & 1 \\
\hline $\mathrm{S}$ & 237 & 36 & 190 & 23 & 328 & 48 & 182 & 22 & 120 & 85 & 7 \\
\hline $\mathrm{Sr}$ & 45 & 2 & 46 & 3 & 25 & 7 & 47 & 5 & 24 & 10 & 1 \\
\hline V & 86 & 6 & 89 & 11 & 969 & 480 & 169 & 28 & 56 & 44 & 1 \\
\hline $\mathrm{Y}$ & 26 & 1 & 29 & 1 & 17 & 5 & 26 & 2 & 28 & 37 & 2 \\
\hline $\mathrm{Zn}$ & 19 & 1 & 21 & 3 & 12 & 3 & 17 & 2 & 14 & 51 & 1 \\
\hline
\end{tabular}


Tabela 4 - Resultados da análise fatorial modo $Q$ com rotação varimax.

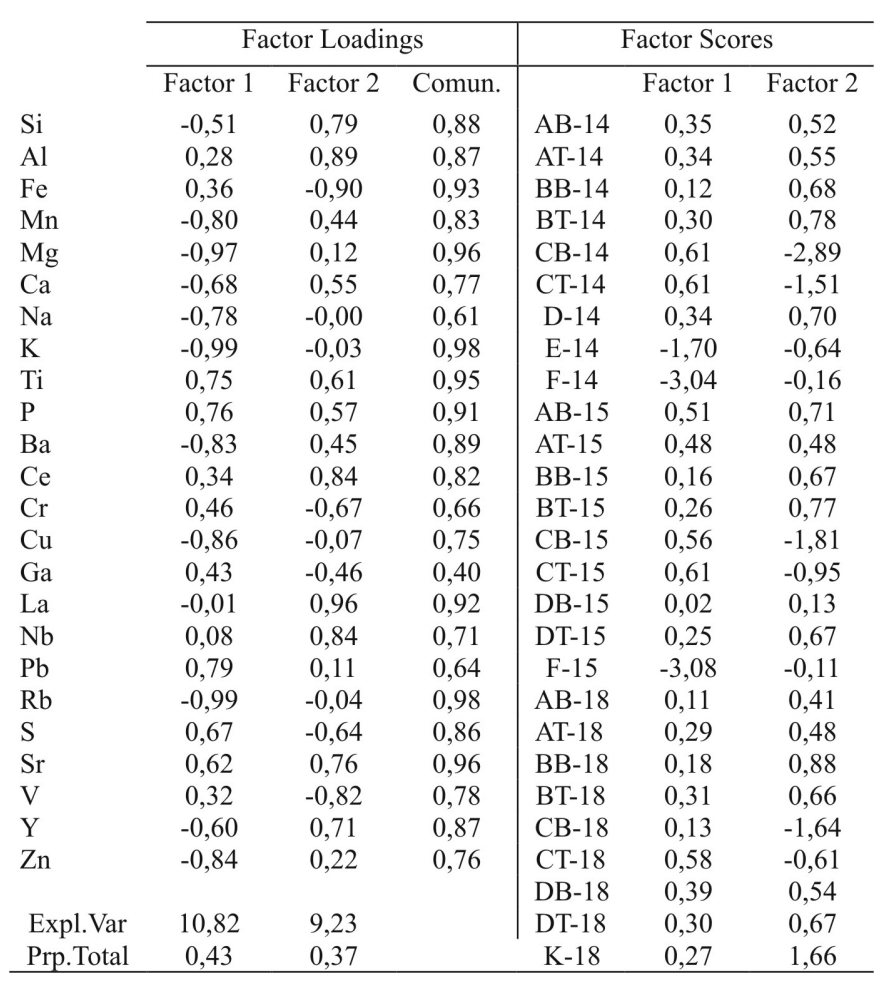

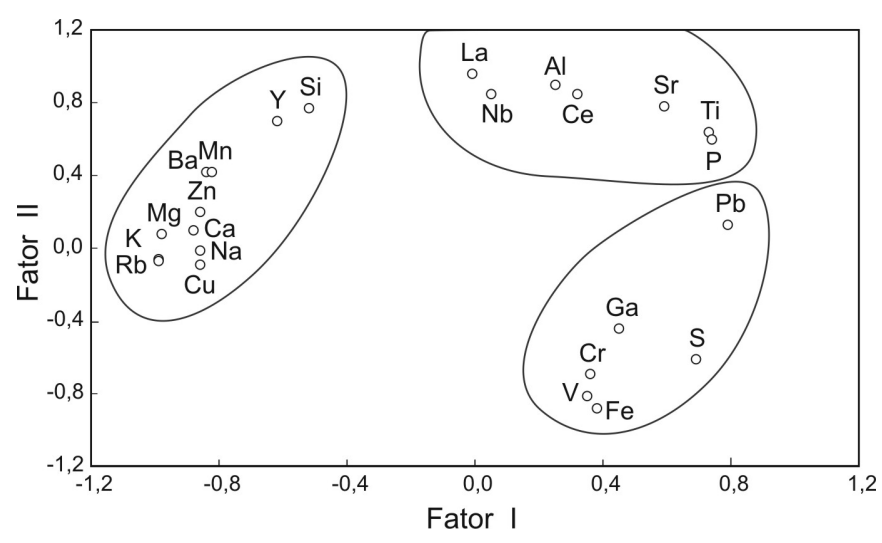

Figura 5 - Projeção das variáveis (elementos) no espaço fatorial $F 1$ versus $F 2$.

portamento das variáveis está satisfatoriamente bem descrito pelo modelo.

O diagrama F1 versus F2 (Fig. 5) permite identificar três grupos de elementos com comportamentos específicos, nucleados em torno dos elementos maiores componentes dos horizontes do perfil de alteração: $\mathrm{Si}, \mathrm{Al}$ e Fe. O Fator 1 opõe os elementos mais solúveis ( $\mathrm{Si}, \mathrm{Mn}, \mathrm{Mg}, \mathrm{Na}, \mathrm{Ca}, \mathrm{K}, \mathrm{Ba}, \mathrm{Cu}, \mathrm{Rb}, \mathrm{Zn}$ ), que apresentam loadings bastante negativos aos elementos menos solúveis, com loadings positivos. O grupo de elementos mais solúveis apresenta suas maiores concentrações no saprólito, concentrações mínimas na couraça e apenas ligeiramente superiores nos latossolos. Parte deles ( $\mathrm{Si}, \mathrm{Na}, \mathrm{K}, \mathrm{Ca}, \mathrm{Mg}, \mathrm{Rb}$ ) está associada a restos dos minerais primários (principalmente micas e talvez vestígios de feldspatos), correspondendo à assinatura geoquímica granítica da rocha parental. Os demais $(\mathrm{Mn}, \mathrm{Ba}, \mathrm{Cu}$ e $\mathrm{Zn}$ ) estão relacionados às concreções manganesíferas neoformadas na base do perfil.

O Fator F2 separa, entre os elementos menos solúveis, os que acompanham $\mathrm{Fe}$ (V, Cr, Ga e S) dos que acompanham Al (Ti, P, Sr, $\mathrm{Ce}, \mathrm{La}, \mathrm{Nb}$ e Y). $\mathrm{Pb}$ fica numa posição intermediária entre os grupos de $\mathrm{Al}$ e de Fe. Os elementos que acompanham Fe apresentam teores crescentes do saprólito até a couraça e uma diminuição de teores mais ou menos acentuada nos latossolos. Esses elementos estão provavelmente associados aos oxi-hidróxidos de ferro, fases dominantes na couraça. De fato, $\mathrm{V}$ e $\mathrm{Cr}$ são elementos de transição comumente encontrados na goethita. Ga, por outro lado, foi durante muito tempo considerado de comportamento semelhante ao do Al, estando principalmente ligado a caolinita e gibbsita nos perfis lateríticos. No entanto, no caso de perfis de evolução complexa, com fases de ferruginização ou de aluminização superimpostas à saprolitização, há dissociação entre esses dois elementos, como foi demonstrado por Hieronymus et al. (2001). Parece ser o caso na cobertura laterítica estudada, onde a correlação $\mathrm{Al}$ versus Ga é praticamente nula $(-0,06)$ e a correlação $\mathrm{Al} / \mathrm{Fe}$ é bastante apreciável $(+0,67)$. Segundo esses autores, com a dissolução da caolinita, Ga é posto em solução, sendo retido parcialmente pelos óxi-hidróxidos de ferro que constituem a couraça.

Os elementos do grupo de $\mathrm{Al}$ apresentam seus teores mínimos na couraça e teores mais elevados nos latossolos, onde apresentam concentrações semelhantes ou maiores que no saprólito. Al é elemento constituinte da caolinita. Os traços encontram-se nos minerais resistentes à alteração como o zircão $(\mathrm{Zr})$ e o anatásio (Ti), e nos eventuais fosfatos residuais ou neoformados (Sr e terras raras) que podem ocorrer em pequenas quantidades no perfil.

BALANÇO DE MASSA Para o cálculo do balanço de massa, o material parental não alterado é normalmente considerado como referência. No entanto, no caso estudado, as amostras de rochas fresca, obtidas através de sondagens, são muito variadas em termos composicionais, em decorrência do hidrotermalismo pervasivo que as afeta. Por esse motivo, optou-se por escolher o saprólito menos alterado como referência (SAP 1: média de F-14 e F-15).

A Tabela 5 mostra os valores de $\varepsilon$ de cada horizonte, expressos em porcentagens, calculados usando as densidades médias e os teores médios de $\mathrm{TiO}_{2}$, sendo o titânio aqui considerado o elemento imóvel. Os valores calculados da função de transporte de massa $\tau$, expressos em porcentagens, constam na Tabela 6 . As médias de $\tau$ para os diferentes horizontes estão graficamente representadas nas figuras 6,7 e 8 . Valores de $\tau$ negativos implicam na exportação dos elementos do perfil (perda), enquanto valores positivos indicam aporte (ganho). Quando um elemento não é

Tabela 5 - Densidades médias, teores de $\mathrm{TiO}_{2}$ e valores de $\varepsilon$ dos horizontes do perfil laterítico.

\begin{tabular}{cccc}
\hline Horizonte & Densidade & $\mathrm{TiO}_{2} \%$ & $\varepsilon$ \\
\hline LA & 1,4 & 0,98 & $-53 \%$ \\
LV & 1,6 & 0,96 & $-58 \%$ \\
C & 2,0 & 0,72 & $-55 \%$ \\
AM & 1,6 & 0,96 & $-58 \%$ \\
SAP2 & 1,7 & 0,38 & $0 \%$ \\
SAP1 & 1,7 & 0,38 & \\
\hline
\end{tabular}


Evolução geoquímica e balanço de massa na formação e degradação de perfis lateríticos encouraçados na área da Fazenda Pison, vale do Rio Tapajós, Amazônia Central

Tabela 6 - Ganhos e perdas de elementos maiores e traço, \% em relação a SAP1.

\begin{tabular}{|c|c|c|c|c|c|c|c|c|c|c|c|c|c|c|c|c|c|c|c|c|c|c|c|}
\hline & Si-t & $\mathrm{Al}-\mathrm{t}$ & Fe- $t$ & $M n-t$ & Mg-t & Na-t & $\mathrm{Ca}-\mathrm{t}$ & K-t & P-t & Ba-t & $\mathrm{Ce}-\mathrm{t}$ & Cr-t & $\mathrm{Cu}-\mathrm{t}$ & Ga-t & La-t & $\mathrm{Nb}-\mathrm{t}$ & $\mathrm{Pb}-\mathrm{t}$ & $\mathrm{Rb}-\mathrm{t}$ & S-t & Sr-t & $\mathrm{V}-\mathrm{t}$ & Y-t & Zn-t \\
\hline \multicolumn{24}{|l|}{ LA } \\
\hline$a b-14$ & -65 & -53 & -37 & -82 & -91 & -100 & -80 & -98 & 1 & -84 & -36 & -68 & -88 & -62 & -54 & -60 & -37 & -99 & 7 & 70 & -17 & -70 & -85 \\
\hline at-14 & -65 & -53 & -37 & -83 & -93 & -90 & -81 & -98 & 1 & -80 & -34 & -70 & -88 & -60 & -54 & -69 & -36 & -99 & -1 & 80 & -25 & -75 & -86 \\
\hline$a b-15$ & -66 & -54 & -38 & -83 & -93 & -100 & -81 & -99 & -5 & -83 & -37 & -71 & -88 & -60 & -57 & -51 & -31 & -99 & -2 & 78 & -22 & -74 & -87 \\
\hline at-15 & -65 & -55 & -39 & -84 & -91 & -100 & -81 & -99 & -3 & -85 & -40 & -73 & -91 & -60 & -59 & -50 & -39 & -100 & 39 & 68 & -26 & -74 & -87 \\
\hline ab-18 & -65 & -51 & -35 & -83 & -89 & -81 & -80 & -98 & -1 & -81 & -42 & -70 & -86 & -59 & -56 & -64 & -38 & -99 & 3 & 78 & -31 & -72 & -84 \\
\hline at- 18 & -66 & -53 & -36 & -84 & -91 & -100 & -81 & -99 & 1 & -82 & -48 & -70 & -84 & -59 & -54 & -58 & -42 & -100 & -1 & 72 & -30 & -74 & -86 \\
\hline LV & & & & & & & & & & & & & & & & & & & & & & & \\
\hline bt-14 & -66 & -51 & -34 & -81 & -88 & -100 & -81 & -97 & 6 & -81 & -36 & -71 & -78 & -56 & -55 & -47 & -37 & -98 & -2 & 81 & -24 & -71 & -84 \\
\hline bb- 15 & -66 & -48 & -14 & -79 & -89 & -90 & -79 & -95 & 11 & -79 & -22 & -52 & -79 & -51 & -48 & -45 & -19 & -96 & -21 & 77 & 6 & -67 & -83 \\
\hline bt- 15 & -65 & -51 & -34 & -81 & -89 & -100 & -80 & -97 & 5 & -81 & -23 & -70 & -85 & -57 & -51 & -52 & -38 & -98 & -11 & 82 & -28 & -68 & -86 \\
\hline bb-18 & -66 & -48 & -27 & -79 & -91 & -100 & -80 & -96 & 10 & -80 & -22 & -66 & -77 & -53 & -51 & -44 & -34 & -97 & -19 & 101 & -25 & -66 & -80 \\
\hline bt-18 & -66 & -50 & -32 & -82 & -89 & -100 & -80 & -98 & 7 & -83 & -34 & -71 & -83 & -54 & -53 & -57 & -32 & -98 & -3 & 77 & -25 & -69 & -84 \\
\hline \multicolumn{24}{|l|}{$\mathrm{C}$} \\
\hline cb-14 & -87 & -55 & 854 & -89 & -93 & -87 & -69 & -99 & 20 & -97 & -60 & 168 & -71 & -11 & -90 & -94 & 7 & -99 & 202 & -6 & 1707 & -80 & -84 \\
\hline ct-14 & -75 & -53 & 381 & -88 & -94 & -100 & -100 & -98 & 4 & -90 & -51 & 148 & -73 & -26 & -84 & -52 & -26 & -99 & 86 & 20 & 975 & -77 & -87 \\
\hline $\mathrm{cb}-15$ & -76 & -58 & 466 & -83 & -90 & -100 & -100 & -97 & 9 & -84 & -31 & 146 & -76 & -21 & -69 & -85 & -17 & -97 & 105 & 35 & 1783 & -76 & -84 \\
\hline cb-18 & -67 & -48 & 593 & -77 & -85 & -100 & -62 & -98 & 25 & -87 & -28 & 33 & -74 & -39 & -60 & -69 & 31 & -99 & 170 & 46 & 405 & -77 & -86 \\
\hline ct-18 & -69 & -50 & 248 & -85 & -93 & -87 & -77 & -99 & 3 & -83 & -44 & 136 & -85 & -36 & -58 & -54 & -11 & -100 & 69 & 53 & 550 & -70 & -88 \\
\hline \multicolumn{24}{|l|}{$\mathrm{AM}$} \\
\hline d-14 & -69 & -55 & 37 & -78 & -88 & -90 & -81 & -95 & 16 & -80 & -32 & -8 & -83 & -59 & -56 & -47 & -25 & -96 & -21 & 84 & 71 & -71 & -89 \\
\hline $\mathrm{db}-15$ & -66 & -52 & 46 & -78 & -86 & -90 & -78 & -94 & 16 & -75 & -21 & 3 & -80 & -51 & -55 & -73 & -12 & -95 & -21 & 71 & 49 & -67 & -83 \\
\hline dt- 15 & -69 & -53 & 41 & -77 & -87 & -90 & -81 & -95 & 18 & -74 & -28 & -18 & -77 & -58 & -52 & -50 & -23 & -96 & -5 & 93 & 55 & -74 & -87 \\
\hline $\mathrm{db}-18$ & -70 & -54 & 54 & -79 & -90 & -90 & -81 & -97 & 14 & -80 & -30 & -3 & -80 & -56 & -51 & -58 & -20 & -98 & -20 & 79 & 61 & -75 & -86 \\
\hline $\mathrm{dt}-18$ & -66 & -52 & 1 & -80 & -89 & -90 & -80 & -97 & 12 & -78 & -29 & -34 & -81 & -54 & -51 & -45 & -30 & -98 & -12 & 92 & 20 & -72 & -88 \\
\hline \multicolumn{24}{|l|}{ SAP } \\
\hline e-14 & 7 & -27 & 37 & -58 & -46 & -50 & 1 & -33 & 51 & -16 & 22 & -59 & -24 & -16 & -34 & -50 & 1 & -48 & 42 & 141 & 28 & -24 & -72 \\
\hline
\end{tabular}
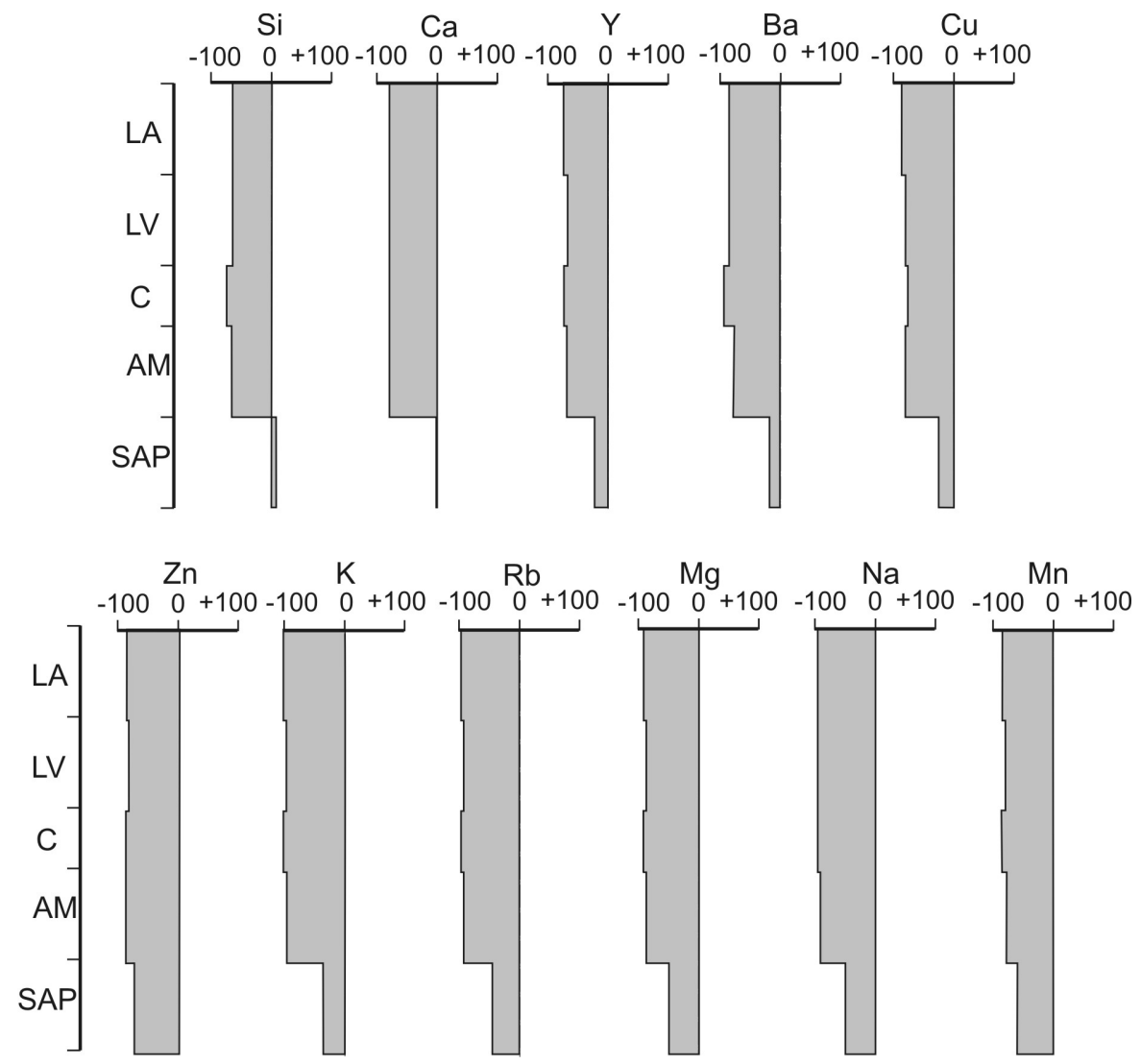

Figura 6 - Ganhos e perdas médias dos elementos do grupo do Si, \% em relação a SAPI. 


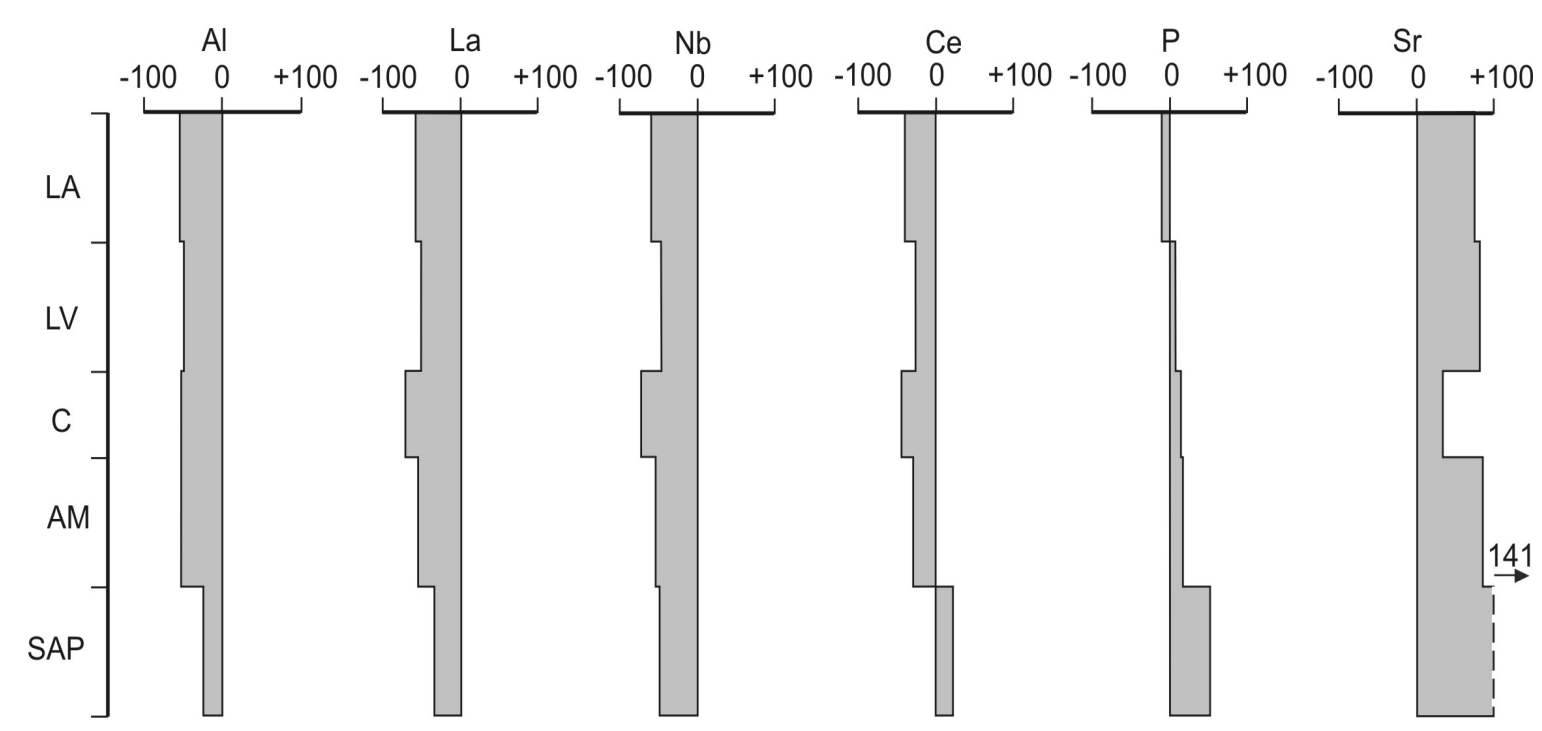

Figura 7 - Ganhos e perdas médias de elementos do grupo do Al, \% em relação a SAP1.

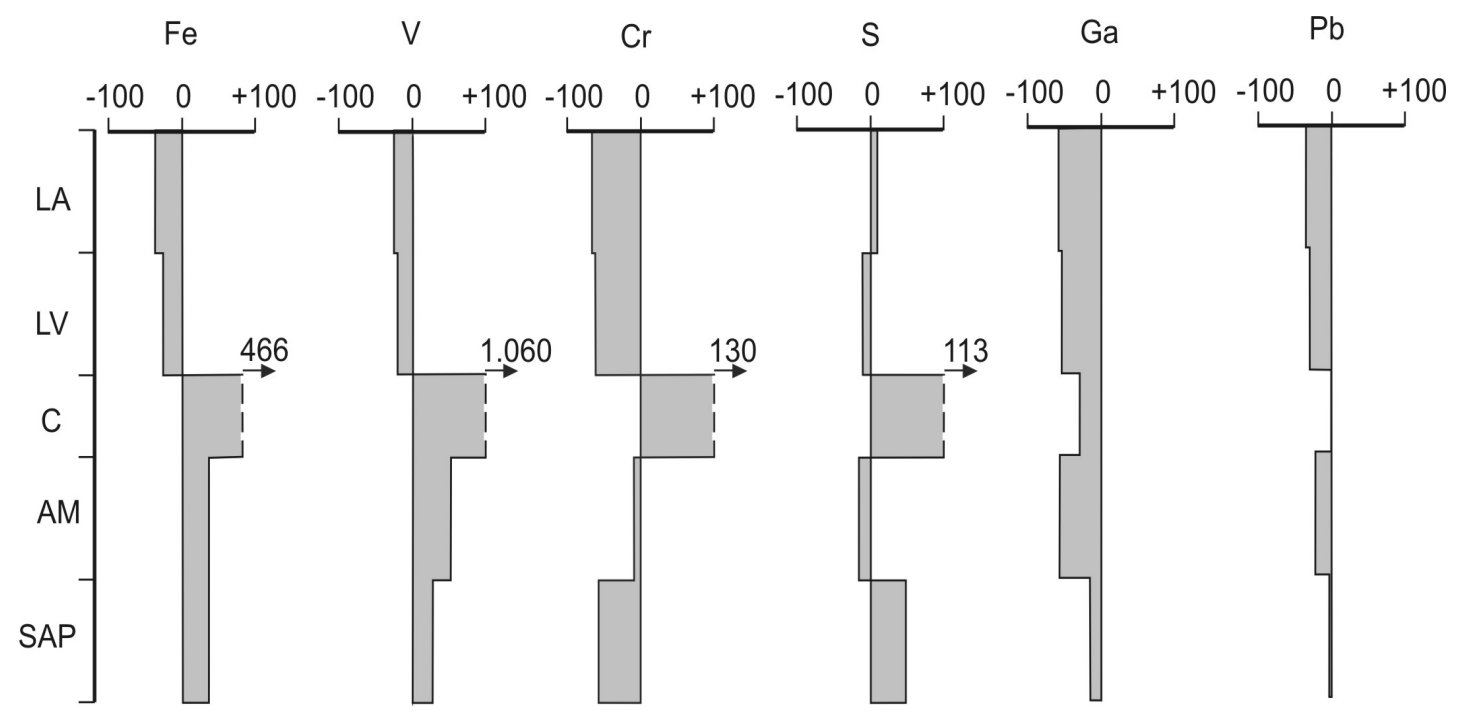

Figura 8 - Ganhos e perdas médias de elementos do grupo do Fe, \% em relação a SAP1.

exportado do perfil $(\tau=0)$, ou é relativamente menos exportado que os demais, ocorre acumulação relativa. Quando há aporte, ocorre acumulação absoluta, o que pressupões uma fonte externa ao perfil ou ao horizonte considerado (Delvigne 1998).

Os resultados do balanço de massa mostram que no saprólito a alteração é isovolumétrica ( $\varepsilon=0$ no saprólito mais alterado, em relação ao saprólito menos alterado). Do saprólito para o horizonte de argila mosqueada observa-se uma perda de volume de $58 \%$, que se mantém entre 50 e $60 \%$ nos horizontes superiores. Isso significa que há acomodação significativa do material alterado a partir do horizonte de argila mosqueada, o que é confirmado pela perda das estruturas primárias à escala macro e microscópica. Compactações ou colapsos dessa ordem de grandeza em perfis lateríticos foram reportados por Colin et al. (1993) no Gabão, Beauvais \& Colin (1993) na República Centro-Africana, e por Boulangé \& Colin (1994) no Brasil, na região do maciço de Passa
Quatro.

Os valores de $\tau$ para os elementos solúveis, cujo comportamento se assemelha ao de $\mathrm{Si}(\mathrm{Ca}, \mathrm{Y} \mathrm{Ba}, \mathrm{Cu}, \mathrm{Zn}, \mathrm{K}, \mathrm{Rb}, \mathrm{Mg}, \mathrm{Na}$ e Mn), mostram, de fato, perdas importantes em todos os horizontes, desde o horizonte de argila mosqueada até os latossolos (Fig. 6). Os elementos do grupo de $\mathrm{Al}$ (La, $\mathrm{Nb}$ e $\mathrm{Ce}$ ) mostram perdas moderadas nos diferentes horizontes do perfil, com perdas um pouco mais significativas na couraça. Fazem exceção a esse comportamento, P que se mantém aproximadamente constante em valores absolutos, e $\mathrm{Sr}$ que parece mostrar ganhos absolutos importantes em quase todos os horizontes (Fig. 7). Tal fato pode ser devido a um erro analítico na determinação do teor de Sr no saprólito parental, que apresenta um conteúdo dosado excepcionalmente baixo desse elemento, por se tratar de saprólito de rocha ácida.

$\mathrm{Fe}$ e alguns dos elementos que o acompanham - V, Cr e S - 
apresentam importante acumulação absoluta já no horizonte de argila mosqueada, e que é intensificada na couraça. Nos latossolos apresentam perdas fracas a moderadas. No caso de $\mathrm{Ga}$ e $\mathrm{Pb}$, não há acumulação absoluta na couraça, porém as perdas nesse horizonte são menores que nos demais (Fig. 8). Importantes acumulações absolutas de Fe em couraças lateríticas, da mesma ordem de grandeza daquelas encontradas na Fazenda Pison, foram constatadas por Freyssinet \& Itard (1997) no Mali, Burkina Fasso e República dos Camarões

DISCUSSÃO E CONCLUSÕES Na área da Fazenda Pison, a cobertura intempérica teve evolução polifásica, que compreendeu um processo de agradação de couraça ferruginosa no seio do perfil laterítico (ferruginização) e um processo superimposto de degradação da couraça com formação de latossolos (deferruginização).

A agradação da couraça iniciou-se a partir da diferenciação do saprólito em horizonte de argila mosqueada por dissolução parcial do quartzo, com conseqüente acumulação de caolinita. Esse fenômeno reflete-se no expressivo aumento da razão quartzo/caolinita do saprólito para a argila mosqueada (Tabela 3 ). Contribuiu também para o expressivo aumento de caolinita neste horizonte a intensa caolinização da mica. Fe também começou a se concentrar, tendo os teores de oxi-hidróxidos atingido 14\% em média (Tabela 3). A acumulação do ferro, principalmente sob forma de goethita, começa a se dar em domínios individualizados neste horizonte.

No desenvolvimento da couraça a dissolução do quartzo intensifica-se, parte da caolinita também dissolve-se, e Fe acumulase, principalmente como hematita, sob forma de nódulos derivados dos domínios ferruginosos da argila mosqueada. O resultado é um material nodular litificado no qual os nódulos estão imersos em matriz areno-argilosa ferruginosa. Os teores de óxi-hidróxidos de ferro chegam a $42 \%$, em média, enquanto quartzo e caolinita, assim como a razão quartzo/caolinita, atingem seus teores mínimos (Tabela 3). Junto com a acumulação de Fe houve também acumulação de V, Cre S. Os demais elementos foram lixiviados em maior ou menor grau. Assim, a assinatura geoquímica do saprólito não foi preservada na couraça, revelando perda da herança geoquímica da rocha parental durante o processo de ferruginização, fato que parece ser comum na gênese da couraças ferruginosas (Tardy et al. 1988, Boeglin \& Mazaltarim 1989, Beauvais \& Colin 1993, Beauvais \& Roquin 1996).

$\mathrm{O}$ balanço de massa mostrou que a formação da couraça foi devida a um aporte de $\mathrm{Fe}$ (acumulação absoluta) que se iniciou no horizonte de argila mosqueada, intensificando-se no horizonte encouraçado. $\mathrm{Na}$ concepção verticalista, que pressupõe que o perfil de alteração encouraçado se desenvolve essencialmente in situ, sem aportes laterais significativos (MacFarlane 1976, Nahon 1986, Tardy 1993), a gênese da couraça é considerada como resultado da dissolução de um espesso pacote de saprólito, a fonte do ferro, situado originalmente acima da couraça atual. Dos constituintes desse saprólito, $\mathrm{Si}$ e Al teriam sido postos em solução e evacuados do perfil, enquanto Fe teria migrado verticalmente para baixo e reprecipitado na couraça. $\mathrm{O}$ mecanismo proposto para a mobilização e concentração de Fe nas couraças é a alternância de condições oxidantes e redutoras que causam sucessivas dissoluções e reprecipitações desse elemento a curtas distâncias. Essa situação é favorecida em condição de clima tropical úmido com uma longa estação seca (Tardy \& Nahon 1985, Nahon 1986). Na gênese das couraças ocorrem também migrações verticais de Fe a distâncias maiores, sob a forma de minúsculas partículas de oxi- hidróxidos que descem no perfil e, finalmente, se acumulam nos poros ocupados por caolinita (Tardy \& Nahon 1985).

A degradação da couraça resultou em latossolos, constituídos essencialmente de quartzo e caolinita. Os teores de oxihidróxidos de ferro não passam de 7\%, em média (Tabela 3). Fe foi, portanto, preferencialmente mobilizado e exportado do perfil, como fica evidente pelo resultado do balanço, que mostra expressivas perdas nesse elemento. A mobilização do ferro é favorecida pela mineralização da matéria orgânica do solo, que consome oxigênio e libera gás carbônico, tornando as soluções percolantes do intemperismo mais ácidas e redutoras, e pela formação de complexos organo-metálicos. O oxi-hidróxido de ferro dominante no latossolo é a goethita, que resultou da hidratação da hematita. A hidratação é normalmente conseqüência da maior disponibilidade de água em clima mais úmido, o que favorece a elevação do lençol freático, produzindo o aparecimento de condições hidromórficas no interior da couraça, o que também facilita a mobilização do ferro. Os grânulos e microgrânulos ferruginosos presentes principalmente no latossolo vermelho representam os últimos vestígios da couraça.

A caolinita da matriz desferrificada e o quartzo subsistiram à degradação da couraça. No entanto, parece haver uma acumulação relativamente maior de quartzo do que de caolinita, o que é evidenciado pelo aumento da razão quartzo/caolinita da couraça para o latossolo amarelo e deste para o latossolo vermelho (Tabela 3). O balanço de massa indica que Al sofreu perdas da mesma ordem de grandeza nos latossolos e nas couraças. Como o balanço é calculado para todos os horizontes tomando-se como referência o saprólito, isto significa que, entre a couraça e os latossolos, houve uma razoável conservação de massa de Al. Para Si, no entanto, a perda foi significativamente maior na couraça que nos latossolos, o que indica aporte do mesmo durante a formação dos latossolos a partir da couraça. Esse aporte deve ter se dado sob a forma de quartzo, única forma de sílica livre nos latossolos. Um agente provável são os cupins, que trazem a terra fina dos horizontes profundos para os mais superficiais, como foi demonstrado por Eschenbrenner (1986) em perfis lateríticos na África.

A transformação das couraças em latossolos acima descrita é comparável à registrada por Beauvais \& Tardy (1991), Bilong et al. (1992) e Bitom e Volkoff(1993) na África central, sob clima tropical úmido. Nahon et al. (1989) descreveram uma situação semelhante àquela da Fazenda Pison, a algumas centenas de quilômetros a leste, na região da Serra do Inajá, no estado do Pará, onde também ocorre a transformação de uma cobertura laterítica comportando uma couraça em um sistema pedológico de latossolos. Esses autores atribuíram a desestabilização da couraça a mudanças climáticas para um regime mais úmido, o que vem ocorrendo no continente sulamericano a partir do final do Mesozóico, em conseqüência da deriva continental (Tardy et al. 1991).

O contexto geomorfológico da área da Fazenda Pison permite emitir uma hipótese para a cronologia do encouraçamento na área. A couraça sustenta uma superfície provavelmente do Neógeno, época do aplainamento Velhas (King 1956). No Mioceno, período no qual o clima tropical era mais contrastado que o atual (Tardy \& Roquin 1998, Horbe et al. 1999), a alteração intempérica das rochas graníticas do vale do rio Tapajós gerou perfis lateríticos portadores de couraça ferruginosa. Essa fase de laterização corresponderia àquela 
reconhecida no Mioceno por Vasconcelos et al. (1994), através de datações radiométricas na região da Serra dos Carajás, e por Théveniaut \& Freyssinet (2002), através de métodos paleomagnéticos na Guiana Francesa e Suriname.

A degradação da couraça, e a geração de latossolos, teriam sido, por sua vez, relacionadas à fase de incisão da superfície Velhas, em condições de clima mais úmido, iniciadas talvez já a partir do Plioceno, e que continuam intermitentemente até hoje. No entanto, os repetidos episódios de clima úmido ainda não foram de magnitude suficiente para destruir completamente a couraça ferruginosa, que permanece como relicto.

Agradecimentos À Fundação de Amparo à Pesquisa do Estado de São Paulo, pelo financiamento do projeto (Proc. 1999/1537-9) e à CPRM pelo apoio logístico e concedeu ao primeiro autor afastamento e suporte financeiro para a realização do doutorado no Instituto de Geociências da Universidade de São Paulo. Aos revisores da RBG pelas sugestões ao manuscrito.

\section{Referências}

Ambrosi J.P. \& Nahon D. 1986. Petrological and geochemical differentiation of lateritic iron crust profiles. Chem. Geol., 57:371-393.

Beauvais, A. 1999. Geochemical balance of lateritization processes and climatic signatures in weathering profiles overlain by ferricretes in Central Africa. Geoch. Cosmoch. Acta, 63:3939-3957.

Beauvais A. \& Tardy Y. 1991. Formation et dégradation des cuirasses ferrugineuses sous climat tropical humide, à la lisière de la forêt équatoriale. Compt. Rend. Acad. Sci., Paris, 309, série II: 553-560.

Beauvais A. \& Colin F. 1993. Formation and transformation processes of iron duricrust systems in tropical humid environment. Chem. Geol., 106:77-101.

Beauvais A. \& Roquin C. 1996. Petrological differentiation patterns and geomorphic distribution of ferricretes in Central Africa. Geoderma, 73:63-82.

Beauvais A. \& Tardy Y. 1993. Degradation and dismantling of iron crusts under climatic changes in Central Africa. Chem. Geol., 107:277-280.

Bilong P., Belinga S.E., VolkoffB. 1992. Séquence d'évolution des paysages cuirassés et des sols ferrallitiques en zones forestières tropicales d'Afrique Centrale. Compt. Rend. Acad. Sci., Paris, 314, série II: 109115.

Bitom D. \& Volkoff B. 1993. Altération déferruginisante des cuirasses massives et formation des horizons gravillonaires ferrugineux dans les sols de l'Afrique Centrale humide. Compt. Rend. Acad. Sci., Paris, 316, série II: 1447-1454.

Boeglin J.L. \& Mazaltarim D. 1989. Géochimie, degrés d'évolution et lithodépendance des cuirassés ferrugineusses de la région de Gaoua au Burkina-Faso. Sci. Géolog. Bulletin, Strasbourg, 42:27-44.

Boulangé B. \& Colin F. 1994. Rare earth element mobility during conversion of nepheline syenite into lateritic bauxite at Passa Quatro, Minas Gerais, Brazil. Applied Geochemistry, 9:701-711.

Braun O.P.G. 1971. Contribuição à geomorfologia do Brasil Central. Rev. Bras. Geogr., 3:3-40.

Brimhall G.H. \& Dietrich W.E. 1987. Constitutive mass balance relations between chemical composition, volume, density, porosity, and strain in metasomatic hydrochemical systems: results on weathering and pedogenesis. Geoch. Cosmoch. Acta, 51:567-587.

Brimhall G.H., Lewis C.J., Ford C., Bratt J., Taylor G., Warin O. 1991. Quantitative geochemical approach to pedogenesis: importance of parent material reduction, volumetric expansion, and eolian influx in lateritization. Geoderma, 51:51-91.

Colin F., Vieillard P., Ambrosi J.P. 1993. Quantitative approach to physical and chemical gold mobility in equatorial rainforest lateritic environment. Earth Planet. Sci. Let., 114:269-285.

Costa M.L. 1991. Aspectos geológicos dos lateritos da Amazônia. Rev.
Bras. Geoc., 21:146-160.

CPRM. 1999. Geologia e Recursos Minerais da Folha Vila Mamãe Anã (SB.21-V-D). Nota Explicativa, escala 1;250.000. CPRM, Manaus, $60 \mathrm{p}$.

Delvigne J.E. 1998. Atlas of micromorphology of mineral alteration and weathering. Mineral. Ass. Canada, $494 \mathrm{p}$.

Eschenbrenner V. 1986. Contribuition des termites a la micro-agrégation des sols tropicaux. Cahiers ORSTOM, série Pédologie, 22:397-408.

Freyssinet P. \& Itard Y. 1997. Geochemical mass balance of gold under various tropical weathering conditions: application to exploration. In: Gubins (ed.), Proc. Exploration 97: 4th Intern. Conf. Min. Explor., 347-354.

Freyssinet P. 1991. Géochimie et minéralogie des laterites du Sud Mali. Évolution du paysage et prospection géochimique de l'or. Thèse Univ. Louis Pasteur, Strasbourg, BRGM Doc. 223, 269p.

Hieronymus B., Kotschoubey B., Boulègue J. 2001. Gallium behaviour in some contrasting lateritic profiles from Cameroon and Brazil. $J$. Geoch. Explor., 72:147-163.

Horbe A.M.C. \& Costa M.L. 1997. Solos gerados a partir do intemperismo de crostas lateríticas sílico-ferruginosas. Acta Amazonica, 27:241-256.

Horbe A.M.C., Costa M.L. da 1999. Relações genéticas entre latossolos e crostas lateríticas aluminosas e alumino-ferruginosas, na região de Paragominas, Pará. Rev. Bras. Geoc., 29:497-504.

Horbe A.M., Soares A.A., Souza V.S.1999. A laterização na evolução morfológica da região de Presidente Figueiredo, Estado do Amazonas. In: SBG/NO, Simp. Geol. Amazônia, Resumos Expandidos: 399-402.

King L.C. 1956. A geomorfologia do Brasil Oriental. Rev. Bras. Geogr., 2:3-265.

MacFarlane M.J. 1976. Laterite and landscape. Acad. Press, London, 151p.

Melfi A. J., Pedro G., Volkoff B. 1979. Natureza e distribuição dos compostos ferríferos nos solos do Brasil. Rev. Bras. Ciên. Solo, 3:47-54.

Nahon D. 1986. Evolution of iron crust in tropical landscape. In: S.M.Coleman \& D.P. Dethier (eds.) Rates of chemical weathering of rocks and minerals. Academic Press, London, pp.169-191.

Nahon D., Melfi A.J., Conte C.N. 1989. Présence d'un vieux système de cuirasses ferrugineuses latéritiques en Amazonie du Sud. Sa transformation in situ en latosols sous la forêt équatoriale actuelle. Compt. Rend. Acad. Sci., Paris, 308, série II: 755-760.

Nahon D. 1991. Introduction to the petrology of soils and chemical weathering. John Wiley, 313p.

Nyobe J.B. 1991. Application of normative calculations in quantitative 
Evolução geoquímica e balanço de massa na formação e degradação de perfis lateríticos encouraçados na área da Fazenda Pison, vale do Rio Tapajós, Amazônia Central

comparative mineralogical studies of bauxite. Ore Geol. Rev., 6:45-50.

RTDM 1995. Relatório de avaliação do potencial aurífero da área da Fazenda Pison (AM). Rio Tinto Desenvolvimentos Minerais, 29p. (Relatório interno).

Santos J.O.S., Groves D.I., Hartmann L.A., Moura M. A., McNaughton N.J. 2001. Gold deposits of the Tapajós and Alta Floresta Domains, Tapajós-Parima orogenic belt, Amazon Craton, Brazil, Miner. Dep., 36:278-299.

Tardy Y. \& Nahon D. 1985. Geochemistry of laterites, stability of Algoethite, Al-hematite and $\mathrm{Fe}^{3+}$-kaolinite in bauxites and ferricretes: an approach to the mechanism of concretion formation. Am. J. Sci., 285:865-903.

Tardy Y., Mazaltarim D. Boeglin J.L., Roquin C., Pion J.C., Paquet H., Millot G. 1988. Lithodépendance et homogénéisation de la composition minéralogique et chimique des cuirasses ferrugineuses latéritiques. Compt. Rend. Acad. Sci., Paris, série II, 307:17651772.

Tardy Y., Kobilsek B., Paquet H. 1991. Mineralogical composition and geographical distribution of African and Brazilian periatlantic laterites. The influence of continental drift and tropical palaeoclimates during the past 150 m.y. and implications for India and Australia. J. African Earth Sci., 12:283-295.

Tardy Y. 1993. Pétrologie des latérites et des sols tropicaux. Masson, Paris, 535p.

Tardy Y. \& Roquin C. 1998. Dérive des continents. Paléoclimats et altérations tropicales. BRGM, 473p.

Théveniaut H. \& Freyssinet P. 2002. Timing of lateritisation of the Guyana Shield: synthesis of paleomagnetic resultas from French Guyana and Suriname. Paleogeog. , Paleoclim., Paleoeco., 178:91-117.

Vasconcelos P.M., Renne P.R., Brimhall G.H., Becker T.A. 1994. Direct dating of weathering phenomena by ${ }^{40} \mathrm{Ar} /{ }^{39} \mathrm{Ar}$ and ${ }^{40} \mathrm{~K} /{ }^{40} \mathrm{Ar}$ analysis of supergene K-Mn oxides. Geoch. Cosmoch. Acta, 58:1635-1665.

Ventura L.M., Ávila L.M., Barbosa G.V. 1975. Geomorfologia. In: Levantamento de Recursos Minerais, volume 7, Folha SB.21 Tapajós.Projeto Radam, MME, DNPM, Rio de Janeiro.

Manuscrito A-1492

Recebido em 18 de março de 2004

Revisão dos autores em 5 março de 2005 Revisão aceita em 20 de março de 2005 